\title{
La investigación-acción en la educación básica en Iberoamérica. Una revisión de la literatura
}

Action Research in Basic Education in Latin America. A Literature Review La recherche-action dans l'éducation basique ibéro-américaine. Une révision de la littérature A pesquisa - ação na educação básica em Ibero-américa. Uma revisão da literatura

Fecha de recepción: 24 DE AGOSTO DE 2016/Fecha de aceptación: 25 DE JULIO DE 2017/Fecha de disponibilidad en línea: 1 DE DICIEMBRE DE 2017

Encuentre este artículo en http://magisinvestigacioneducacion.javeriana.edu.co/

\begin{abstract}
Resumen
Este artículo de revisión presenta la revisión de la literatura de 57 artículos publicados entre 2000 y 2014, que desarrollan experiencias de investigación-acción (IA) en aulas de primaria y secundaria en Iberoamérica, y analiza la finalidad de la IA, las temáticas, la posición del investigador, sus aportes y limitaciones. Los resultados revelan que la IA se orienta a la mejora y transformación de la práctica en áreas curriculares no siempre evaluadas por los sistemas educativos. El maestro es participante, y no protagonista (maestro-investigador o coinvestigador) o autor de la investigación sobre su propia práctica.
\end{abstract}

\section{Palabras claves}

Investigación pedagógica; investigación-acción; enseñanza primaria; enseñanza secundaria; maestro-investigador

Para citar este artículo / To cite this article / Pour citer cet article / Para citar este artigo

Díaz-Bazo, Carmen del Pilar (2017). La investigación-acción en la educación básica en Iberoamérica. Una revisión de la literatura. magis, Revista Internacional de Investigación en Educación, 10 (20), 159-182. https://doi.org/10.11144/Javeriana.m10-20.iaeb 


\section{Keywords}

Pedagogical research; action research; primary education; secondary education; teacher-researcher

\section{Mots clés}

Recherche pédagogique; recherche-action enseignement primaire; enseignement secondaire; enseignant-chercheur

\section{Abstract}

This article presents the literature review of 57 articles published between 2000 and 2014, which developed action research experiences in primary and secondary classrooms in Ibero-America. The paper analyzes the purpose of action research, the themes, the researcher's position, their contributions and limitations. Results reveal that action research aims to improve and transform the practice in curricular areas, which are not always evaluated by educational systems. The teacher is a participant, not a protagonist (teacher - researcher or co-researcher) or author of the research about his own practice.

\section{Résumé}

L'article de synthèse présente la révision de la littérature de 57 articles publiés entre les années 2000 et 2014, qui développent expériences de recherche-action (RA) dans les salles de classe de primaire et secondaire à Ibéro-Amérique. On analyse la finalité de la RA, les sujets, la posture du chercheur, ses contributions et contraintes. Les résultats montrent que la RA s'oriente à l'amélioration et transformation de la pratique dans le domaine curriculaire pas toujours évalué par les systèmes éducatifs. L'enseignant est participant, et non pas protagoniste (enseignant-chercheur ou cochercheur) ou bien auteur de la recherche sur sa propre pratique.

\section{Palavras-chave}

Pesquisa pedagógica; pesquisa-ação; ensino primário; ensino secundário; maestro-investigador

\section{Resumo}

Este artigo apresenta a revisão da literatura de 57 artigos publicados entre os anos 2000 e 2014, que desenvolvem experiências de pesquisa-ação em salas de primária e secundária em Ibero-américa. Analisa-se a finalidade da pesquisa-ação, as temáticas, a posição do pesquisador, sua contribuição e suas limitações. Os resultados revelam que a pesquisa-ação se orienta à melhora e transformação da prática em áreas curriculares nem sempre avaliadas pelos sistemas educativos. O maestro é participante e não protagonista (maestro-pesquisador ou co-pesquisador) ou autor da pesquisa sobre sua própria prática. 


\section{Introducción}

Desde el origen de la investigación-acción (IA), se ha transitado por distintas concepciones, enfoques y tradiciones que hacen difícil definirla unívocamente (McKernan, 1999; McNiff, 2014; Pérez-Serrano, 1990; Reason \& Bradbury, 2001; Rowell, Polush, Riel \& Bruewer, 2015). Jean McNiff (2014) plantea que hay dos formas de entenderla: la IA como práctica desarrollada por los individuos o los colectivos para mejorar lo que hacen, y la IA como método trabajado por investigadores - por lo general, del mundo académico - que pueden formar parte o no de la situación que se analiza.

En el primer caso, se puede situar la IA participativa en educación popular en América Latina, promovida por Paulo Freire y Orlando Fals-Borda, con una orientación a la transformación social y política, y al empoderamiento de las comunidades, que ha estado muy presente en el campo, pero poco publicada en revistas académicas (Flores-Kastanis, Montoya-Vargas \& Suárez, 2009). De otro lado, en algunos países de América Latina, se han promovido políticas de desarrollo profesional docente basadas en la IA y en la práctica reflexiva con el objetivo de que sean los maestros quienes reflexionen y transformen sus prácticas; en este caso, es mucho menos lo que ha sido escrito por ellos.

En el segundo caso, desde la academia, se ha producido mucho más. Bob Dick $(2006,2009$, 2011) presenta la revisión de libros publicados principalmente en el mundo anglosajón, sobre IA en distintos períodos y en distintas disciplinas. En el campo educativo, están Lawrence Stenhouse (1987), Wilfred Carr y Stephen Kemmis (1988), John Elliott (1993), Stephen Kemmis y Robin McTaggart (1998), James McKernan (1999), Peter Reason y Hilary Bradbury (2001), además de autores iberoamericanos como Gloria Pérez-Serrano (1990), Julia Blández-Ángel (1996), Antonio Latorre (2003) y Bernardo Restrepo-Gómez (2004), entre otros.

Si bien se considera a Kurt Lewin como el padre fundador de la IA a mediados de los años 40, James McKernan (1999) reconoce su uso antes de la conceptualización lewiniana en los escritos de John Collier (1933-1945). En los años 50, Stephen Maxwell Corey, Hilda Taba y Elizabeth Goudy Noel fueron considerados hitos representativos de la IA para la investigación del currículo en Estados Unidos (Pérez-Serrano, 1990). Luego, a partir de los años 70, la IA en educación resurgió como un método de investigación que buscaba cambiar o mejorar las prácticas educativas, las concepciones del maestro y el contexto donde se realiza a partir de la indagación autorreflexiva (Carr \& Kemmis, 1988; Elliott, 1990; Stenhouse, 1987).

En la IA, el maestro que investiga su práctica se problematiza sobre sus concepciones y prácticas, es decir, deja de entenderlas como obvias, evidentes o naturales, y convierte sus aulas en laboratorios y sus acciones en hipótesis. Ello supone un proceso cíclico o en espiral de varios momentos: el reconocimiento de un problema que se desea mejorar, la formulación de una hipótesis y plan de acción, la acción y la reflexión, y así, sucesivamente, en varios ciclos de acción. La reflexión, la construcción de teoría a partir de la práctica, la participación colaborativa, la innovación, y el cambio o mejora de la práctica aparecen en la literatura como características claves de la IA, que la diferencian de otros métodos de investigación, y que permiten empoderar a los maestros como profesionales e investigadores reflexivos.
Descripción del artículo | Article description | Description de l'article | Artigo descrição

Este artículo de revisión, derivado del proyecto La investigación acción en aulas de educación primaria y secundaria en lberoamérica, se centró en la revisión de la literatura de 57 artículos publicados en revistas académicas que describen la aplicación de la investigación-acción (IA) en aulas de primaria y secundaria en Iberoamérica. Como docente formadora en investigación e investigadora, me interesó conocer y sistematizar qué se está produciendo en este campo, sobre todo cuando la IA está formando parte de los programas de desarrollo profesional en mi país. Este proyecto formó parte de mi plan de trabajo anual de 2015 como docente en la Pontificia Universidad Católica del Perú. 


\section{Estudios previos de revisión de la literatura sobre investigación-acción en educación}

Esta parte recoge algunos estudios basados en la revisión de la literatura sobre IA realizados en los últimos años, en especial en el ámbito de la educación básica y de la educación superior. Entre ellos, encontramos el trabajo de Nelofer Halai (2012), quien realiza una metasíntesis cualitativa de 20 tesis de maestría realizadas por maestros de escuela que incorporan estrategias innovadoras en sus clases de ciencias en Pakistán usando la IA. Los resultados señalan que la IA contribuye al desarrollo de tres dominios respecto al conocimiento docente: conocimiento pedagógico, conocimiento de la asignatura y conocimiento didáctico del contenido. Sin embargo, encuentra problemático articular la innovación en la IA con las exigencias de los métodos actuales de evaluación.

De otro lado, María Jesús Romera-Iruela (2014) identifica 83 artículos publicados en revistas de educación española entre 1989 y 2010, y analiza el aporte de la IA en la didáctica, en la práctica docente, en la formación del profesorado y en el desarrollo profesional en el campo de las ciencias experimentales. Concluye que hay una incidencia positiva de la IA en estos ámbitos, aunque es muy poco lo que aún se ha publicado.

Paul Gibbs, Patricia Cartney, Kate Wilkinson, John Parkinson, Sheila Cunningham, Carl James-Reynolds, Tarek Zoubir, Venetia Brown, Phil Barter, Pauline Sumner, Angus MacDonald, Asanka Dayananda y Alexandra Pitt (2017) estudian la literatura producida desde 2005 sobre IA en la educación superior encontrada en revistas sobre educación en in-house database. Los autores hallan dos grandes temas sobre IA: la práctica de la enseñanza y el compromiso de los estudiantes. Para el primer tema, los estudios se han centrado en vincular la IA con la justicia social y la emancipación; con el desarrollo institucional (lo que supera la tradicional división entre formación, investigación y administración); y con el desarrollo curricular. En el segundo, el foco de atención es la crítica y retroalimentación que realizan los estudiantes sobre la enseñanza de los profesores y su compromiso en el aprendizaje. En ambos temas, se comprueba que la IA es un enfoque importante para la investigación, la reflexión y la innovación en la práctica.

Otro estudio es el desarrollado por Michelle Vaughan y Gail Burnaford (2016), quienes - mediante la revisión de la literatura de artículos, tesis de maestría y doctorado, y capítulos de handbooks publicados entre 2000 y 2015 especialmente en Estados Unidos - analizan el uso de la IA como contenido y metodología en los programas de posgrado en educación (maestrías y doctorados). Un primer hallazgo se refiere al estatus y legitimización de la IA en estos programas respecto a la investigación "tradicional". En segundo lugar, analizan el uso y profundidad de la IA según las metas y objetivos del programa vinculados con la reflexión en la práctica; la participación, la emancipación y la crítica; y el liderazgo profesional. Finalmente, muestran el uso creciente de la IA en los programas doctorales y las discusiones en la academia respecto a su validez.

Por su parte, Christa Fouché y Laura A. Chubb (2016) seleccionan 39 artículos para identificar los desafíos que enfrentan los investigadores que usan la IA para respetar los principios éticos de la investigación, en especial en esta, que se define como participativa, involucra a los distintos sujetos y busca la emancipación y transformación de ellos. Si bien esta revisión no se enmarca solo en el ámbito educativo, es, quizás, uno de los temas poco abordados en la literatura sobre IA; esto exige repensar y adecuar sus criterios, más aún en un tipo de investigación que involucra a otros. 
En estas revisiones de literatura presentadas, se comprueban tres tendencias respecto al uso de la IA. La primera es su contribución a la innovación, y mejora y transformación de las prácticas pedagógicas de los docentes, aspecto que confirma uno de los principales objetivos de la IA. La segunda es el debate en relación con el estatus "científico" de la IA y su legitimidad en las tesis de posgrado, e incluso — nos atrevemos a añadiren algunas revistas indizadas. Al respecto, se reconoce que hacer y escribir IA supone criterios de calidad distintos a los acostumbrados sin perder la rigurosidad (McNiff, 2014; Zuber-Skerritt \& Fletcher, 2007), lo que exige un aprendizaje para el maestro-investigador y para los pares evaluadores. La tercera es la discusión sobre las formas de mostrar y evaluar los principios éticos de la investigación, dado su carácter colaborativo (los sujetos son parte de la investigación) y transformador de la práctica.

Este estudio aporta, en una primera aproximación, a la IA realizada en Iberoamérica en aulas de primaria y secundaria que, como se ha visto, ha sido poco recogida en estas revisiones de la literatura.

\section{Metodología}

Para el desarrollo de este estudio, la revisión de la literatura se utilizó como método que permite identificar, evaluar y sintetizar el cuerpo de conocimientos producidos por investigadores, académicos o prácticos (Booth, Papaioannou \& Sutton, 2012; Randolph, 2009). Como una primera exploración, interesó analizar la aplicación de la IA en contextos de aula de educación primaria y secundaria en Iberoamérica mediante la revisión de los artículos académicos publicados entre 2000 y 2014. Las preguntas que guiaron el estudio fueron las siguientes: ¿cuál es la producción académica en Iberoamérica sobre estudios que aplican la IA en la educación básica?, ¿cómo se fundamenta la IA y qué autores son usados para ello?, ¿en qué temáticas se realiza la IA?, ¿quiénes la desarrollan y la escriben?, ¿cuál es el aporte de la IA para investigar en las aulas?, ¿qué dificultades se presentan en el desarrollo de la IA?

En la selección de los artículos que forman parte del estudio, se consideraron los siguientes criterios de inclusión:

- Estudios empíricos que explicitan el uso de la investigaciónacción en el título, resumen o palabras claves.

- Estudios desarrollados en contextos de aula de primaria o secundaria (educación básica) con grupos de alumnos identificados.

- Estudios desarrollados en aulas de escuelas de Iberoamérica.

- Artículos en revistas arbitradas en línea y con texto completo.

- Artículos publicados entre 2000 y 2014.

- Artículos escritos en español.

En ese sentido, se excluyeron artículos vinculados con la formación del profesorado, formación inicial docente o desarrollo profesional, y aquellos estudios desarrollados en aulas de preescolar, ámbitos universitarios o en contextos no formales.

Para la búsqueda de los artículos, se usó las bases de datos de EBSCO', Scientific Electronic Library Online (SciELO), Red de Revistas Científicas de América Latina y el Caribe, España y Portugal (Redalyc), Dialnet,

1 Aquí nos referimos a EBSCO Discovery Service (EDS), un índice de recursos de información que permite recuperar, desde una plataforma de búsqueda unificada, los contenidos de colecciones suscritas por la Biblioteca de la Universidad en la que la autora labora. 
y Directory of Open Access Journals (DOAJ). El descriptor usado fue investigación-acción combinado con otros descriptores, como educación primaria, educación secundaria, aula, enseñanza y didáctica. De acuerdo a las posibilidades de cada base de datos, se aplicaron los siguientes filtros: disciplina (educación, ciencias sociales o ciencias humanas), idioma (español), año (2000-2014). La búsqueda se realizó considerando que el descriptor investigación-acción esté presente en el título, el resumen o las palabras clave del artículo. Con ello, cada una de las bases arrojó distinto número de artículos².

A partir de ello, se obtuvo una primera lista de 82 documentos. Luego de la lectura de cada artículo, se eliminaron aquellos que no cumplían todos los criterios de inclusión. Asimismo, se encontraron dos casos de duplicidad que relatan el desarrollo de una misma investigación publicados en revistas y años diferentes. Se eliminó uno de los artículos duplicados y se seleccionó el más reciente. Finalmente, para este estudio, se identificaron 57 artículos.

Para el análisis de los artículos, se trabajó con el software Atlas-ti y tablas dinámicas de Excel; esto permitió organizar la información de acuerdo a las categorías diseñadas y descubrir subcategorías o propiedades. En la tabla 1, se muestran las categorías seleccionadas.

Tabla 1

Categorías de estudio

\begin{tabular}{|c|c|}
\hline Categoría & Subcategoría \\
\hline Producción académica & $\begin{array}{l}\text { - } \quad \text { Rúmero de artículos por año } \\
\text { - } \text { estudiostas académicas en las que se publican } \\
\text { - Los autores de los artículos }\end{array}$ \\
\hline Justificación de la IA & $\begin{array}{l}\text { - Fundamentación de la IA } \\
\text { - Autores más citados }\end{array}$ \\
\hline Contexto de la IA & $\begin{array}{l}\text { - País donde se desarrolla } \\
\text { - Nivel educativo } \\
\text { - Temática } \\
\text { - Posición del investigador: interno/externo }\end{array}$ \\
\hline Efectos de la IA & $\begin{array}{l}\text { - } \text { Aportes de la IA } \\
\text { - Limitaciones de la IA }\end{array}$ \\
\hline
\end{tabular}

Fuente: elaboración propia

\section{Resultados}

La producción académica sobre investigación-acción en aulas de educación básica

En las dos últimas décadas, la IA hace parte de los procesos orientados a formar maestros investigadores, más críticos y reflexivos, capaces de mejorar su práctica. Sin embargo, la investigación que realizan los docentes en sus aulas no es tan difundida por las revistas académicas. Eduardo Flores-Kastanis, Juny Montoya-Vargas y Daniel H. Suárez (2009) dan cuenta de esta situación al señalar que la IA —en ese caso, participativa y en América Latina - es "casi invisible en las publicaciones académicas, pero muy visible en las aulas y las escuelas" (p. 290). Por el número de publicaciones encontradas, esta situación se mantiene.

2 Aquí mostramos algunos de los datos más significativos que arrojó la búsqueda realizada. En EBSCO: 55 artículos con el descriptor investigación-acción en el título; 92 con IA + educación primaria; 83 con IA + educación secundaria. En SciELO: 521 artículos. En Dialnet: 346 artículos con investigación acción + aula. En DOAJ: 45 artículos. En Redalyc: 46 artículos con IA en el título y 114 con IA en palabras claves. 
La búsqueda arrojó 57 artículos entre 2000 y 2014. Como se aprecia en el gráfico 1, la producción de artículos académicos que describen y analizan experiencias de IA realizadas en contextos de aula crece a partir de 2008. El 52\% se concentra entre 2011 y 2014.

Gráfico 1

Distribución de los artículos académicos según año de publicación

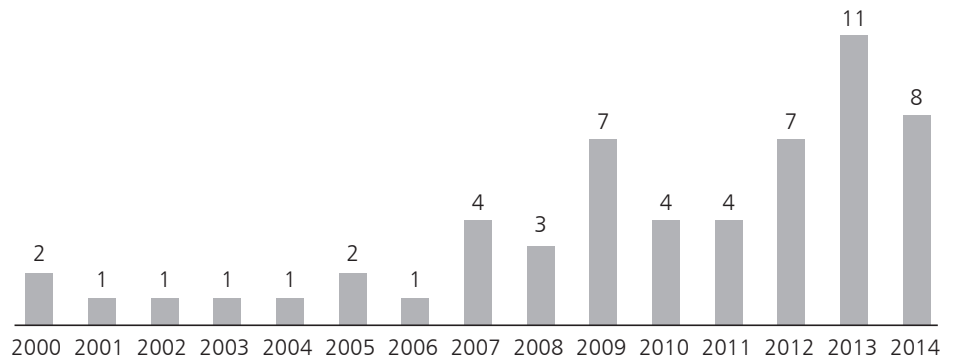

Fuente: elaboración propia

Estas publicaciones aparecen en 43 revistas académicas, principalmente españolas, como es de suponer, dada la mayor productividad académica de España frente a los países de América Latina. Educere: Revista Venezolana de Educación reúne cuatro de los artículos estudiados.

De otro lado, gran parte de los artículos se difunde en revistas especializadas (tabla 2), por ejemplo, en educación física y deporte, en ciencias y matemática, o en educación musical. Ello muestra una tendencia a difundir las investigaciones basadas en la IA en aquellas revistas de corte más didáctico, práctico y especializado.

Tabla 2

Relación de revistas académicas

\begin{tabular}{l|c|l|c}
\hline $\begin{array}{l}\text { Revistas académicas } \\
\text { (en orden alfabético) }\end{array}$ & $\begin{array}{l}\text { Total de } \\
\text { artículos }\end{array}$ & $\begin{array}{l}\text { Revistas académicas } \\
\text { (en orden alfabético) }\end{array}$ & $\begin{array}{l}\text { Total de } \\
\text { artículos }\end{array}$ \\
\hline Acción Pedagógica & 1 & Punto Cero & 1 \\
\hline Acción Motriz & 1 & $\begin{array}{l}\text { Retos. Nuevas Tendencias en Educación Física, } \\
\text { Deporte y Recreación }\end{array}$ & 3 \\
\hline Ágora para la EF y el Deporte & 1 & Revista Científica & 2 \\
\hline Anales de la Universidad Metropolitana & 1 & Revista de Educación & 1 \\
\hline Apunts, Educación Física y Deportes & 1 & Revista de Educación Laurus & 1 \\
\hline Educación Matemática & 1 & Revista de Investigación & 1 \\
\hline Educere: Revista Venezolana de Educación & 4 & $\begin{array}{l}\text { Revista Electrónica Actualidades Investigativas } \\
\text { en Educación }\end{array}$ & 1 \\
\hline EmásF, Revista Digital de Educación Física & 1 & $\begin{array}{l}\text { Revista Electrónica Complutense de } \\
\text { Investigación en Educación Musical }\end{array}$ & 2 \\
\hline Enseñanza de las Ciencias & 2 & $\begin{array}{l}\text { Revista Electrónica de Investigación y } \\
\text { Docencia Creativa (ReiDoCrea) }\end{array}$ & 1 \\
\hline Enseñanza de las Ciencias Sociales & 1 & $\begin{array}{l}\text { Revista Electrónica de LEEME (Lista Electrónica } \\
\text { Europea de Música en la Educación) }\end{array}$ & 3 \\
\hline Enunciación & 2 & Revista Electrónica de Tecnología Educativa & 1 \\
\hline
\end{tabular}




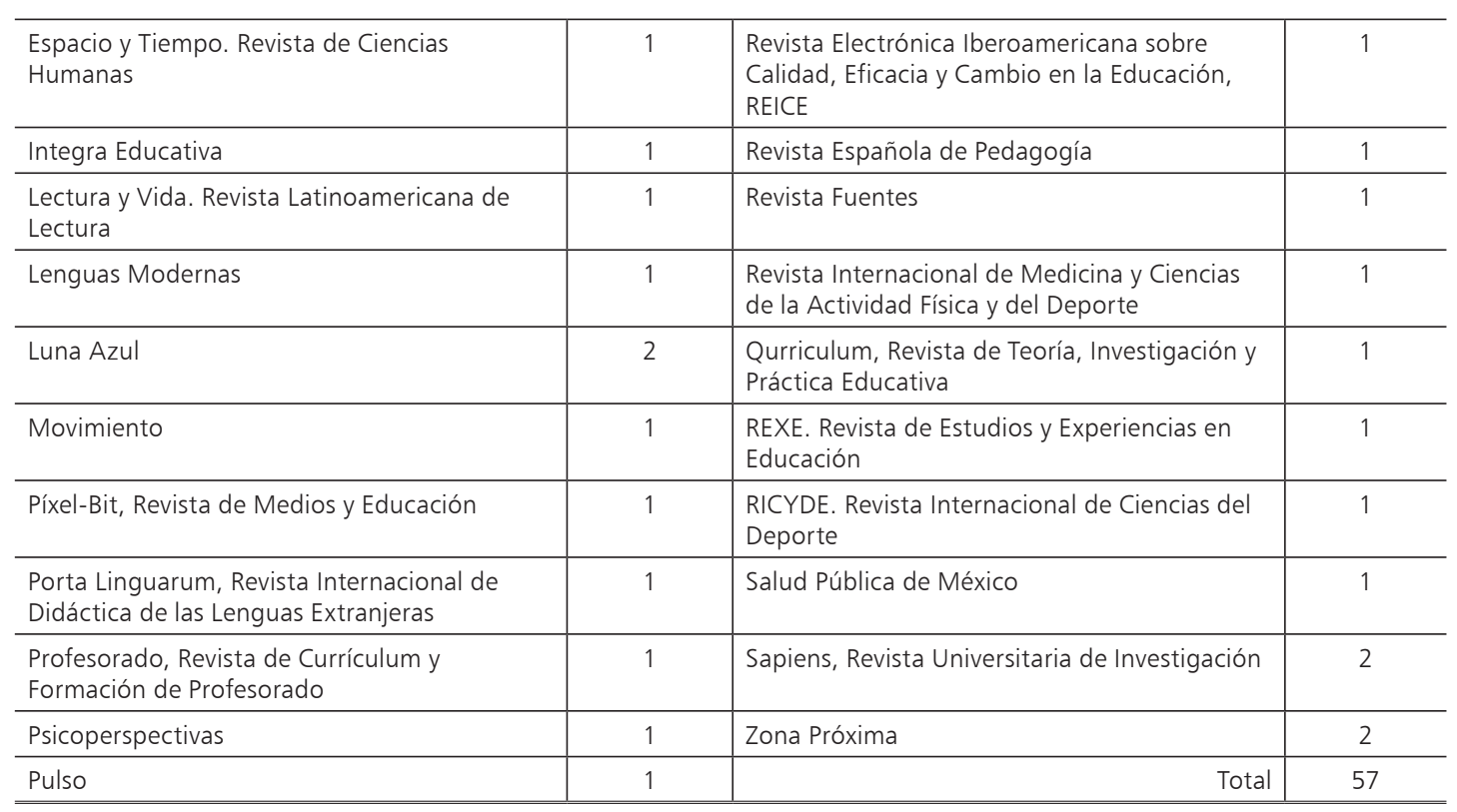

Fuente: elaboración propia

En relación con los autores de los artículos, se identifican 106. El $42 \%$ de los artículos han sido escritos por un solo autor y el 37\%, por dos autores. Resulta interesante analizar quién escribe el artículo, debido a que la IA pretende ser un método de investigación usado por los docentes de aula para mejorar su práctica educativa (Elliott, 1990). Al revisar las instituciones de procedencia que señalan los autores de los textos, en 37 artículos, sus autores se afilian a una universidad; en diez, los autores pertenecen a una institución de educación básica; y, en cinco, la coautoría es repartida entre un autor vinculado con una universidad y otro con una institución escolar. Estos hallazgos, y otros que se revisarán más adelante, permiten sugerir la siguiente clasificación (tabla 3 ) que va de autores-docentes de aula, quienes realizan la IA, hasta autores académicos — universitarios, que reportan resultados de IA desarrollada por docentes de aula. Además, en menor proporción, hay autores-estudiantes de maestría o vinculados a organismos públicos de educación que escriben con autores universitarios.

Tabla 3

Afiliación de los autores de los artículos sobre IA

\begin{tabular}{l|l|c}
\hline Afiliación & Descripción & Total de artículos \\
\hline $\begin{array}{l}\text { Autores afiliados a una institución de } \\
\text { educación básica }\end{array}$ & Escriben sobre su propia experiencia de IA & 10 \\
\hline $\begin{array}{l}\text { Autores afiliados a una institución de } \\
\text { educación básica en coautoría con } \\
\text { académicos universitarios }\end{array}$ & $\begin{array}{l}\text { Escriben como coautores sobre la experiencia } \\
\text { realizada en el aula }\end{array}$ & 5 \\
\hline $\begin{array}{l}\text { Autores académicos afiliados a una } \\
\text { universidad }\end{array}$ & $\begin{array}{l}\text { Escriben sobre experiencia de IA realizada en una } \\
\text { escuela/aula por uno o varios docentes }\end{array}$ & 37 \\
\hline $\begin{array}{l}\text { Autores estudiantes de maestría o de } \\
\text { organismos públicos de educación en } \\
\text { coautoría con académicos universitarios }\end{array}$ & $\begin{array}{l}\text { Escriben como coautores sobre la experiencia } \\
\text { realizada en el aula }\end{array}$ & 5 \\
\hline \multicolumn{2}{|c}{} & \multicolumn{1}{c}{ Total } \\
\hline \hline
\end{tabular}

Fuente: elaboración propia 
Si la IA compromete a los prácticos para que puedan mejorar sus propias prácticas, se observa que, en muchos casos, no son ellos los que escriben directamente sobre la IA, con lo que se mantiene una jerarquía entre los roles de investigador (académico universitario) y práctico (maestro de aula) (McNiff, 2014). Los docentes universitarios cuentan con más acceso a escribir en revistas académicas y los maestros pueden acceder a ellas en conjunto con autores universitarios. Esto revela o bien la poca práctica de escritura académica que tienen los maestros de aula, o bien la poca legitimidad de estos estudios en revistas arbitradas o indizadas, sobre todo cuando pueden ser escritos por maestros ajenos al mundo académico. Sin embargo, esta realidad está cambiando en otras regiones en la medida en que más maestros acceden a estudios de posgrado, y vinculan sus tesis con su ejercicio profesional (Halai, 2012; Herr \& Anderson, 2015; McNiff, 2014; Zuber-Skerritt \& Fletcher, 2007).

La justificación de la investigación-acción: mejorary transformar la práctica pedagógica

Los artículos se refieren a la IA indistintamente como enfoque, método, metodología, modelo, perspectiva, modalidad, marco o estudio. Al referirse a la IA, algunos la llaman IA colaborativa (9 artículos), IA participativa (6 artículos), e IA participativa y colaborativa (1 artículo) para enfatizar su carácter participativo y colaborativo.

A su vez, hay diversas perspectivas desde donde se concibe, fundamenta o justifica el uso de la IA en el desarrollo de la investigación presentada en los artículos (tabla 4). Los autores reconocen, principalmente, la IA como la investigación que se orienta a la mejora de la práctica educativa o pedagógica, y que busca el cambio o la transformación de esta (Rowell, Polush, Riel \& Bruewer, 2015). De acuerdo con James McKernan (1999), se estaría hablando de la investigación desde el enfoque interpretativo en la línea de John Elliott (1993). Son menos los que explicitan el enfoque sociocrítico y resaltan su carácter emancipador o la indagación autorreflexiva para comprender las prácticas y las situaciones en las que ellas se realizan, en la línea de Wilfred Carr y Stephen Kemmis (1988). De este modo, en estos artículos, no solo se están refiriendo a mejorar una práctica en sí misma, sino a reconocer el carácter social y político de la práctica.

En otro grupo de artículos, se justifica la IA vinculada al desarrollo profesional del docente, al nuevo rol del docente como investigador de su práctica y a romper con la tradicional división investigadordocentes investigados.

Tabla 4

Justificación de la IA

Justificación de la IA
(categorías)

Mejora de la práctica educativa o pedagógica

\section{Autores de los artículos}

Carme Carrillo-Aguilera \& Mercè Vilar i Monmany (2009); Josep Coral \& Teresa Lleixà-Arribas (2013); Francisco Javier Diego-Rasilla (2007); Fernando Jesús Fariña-Pérez \& Juan José Sosa-Alonso (2011); Javier Fernández-Río, Juan F. Medina-Gómez, Jacob Garro-García \& M. Pérez-González (2001); Roberto Guillén-Correas \& Carlos Peñarrubia-Lozano (2013); Rosario Gutiérrez-Cordero, Antonio Cremades-Begines \& Benjamín Perea-Díaz (2011); María Elena Hidalgo (2009); Teresa Lleixà, Miguel Ángel Torralba \& Sergio Roberto Abrahão (2010); Víctor M. López-Pastor (2008); Núria Monzonís-Martínez \& Marta CapllonchBujosa (2014); José Palazón-Herrera (2013); José A. Pareja-Fernández de la Reguera \& Beatriz Pedrosa-Vico (2012); Zonaida Ramírez \& Carmen Teresa Chacón (2007); Víctor Ríos-Cortázar, Alejandra Gasca-García, Mónica FrancoMartínez \& Lizbeth Tolentino-Mayo (2014); Deyse Ruiz \& Marianela García (2003); Miriam Terán de Serrentino \& Lizabeth Pachano-Rivera (2009); Helda Toloza, Norma Barletta \& Francisco Moreno (2013); Carolina Villagra-Bravo \& Cristhian Castillo-Melgarejo (2010); Mario Zárate (2012).

Transformación o cambio de la práctica, la escuela o la realidad educativa

\begin{tabular}{l|l} 
María del Carmen Conde-Núñez, J. Samuel Sánchez-Cepeda \& José María & 15 \\
Corrales-Vázquez (2009); Sandra Milena García-González (2014); Cecilia & \\
González-Terry (2011); Teresa Lleixà, Miguel Ángel Torralba \& Sergio Roberto & \\
Abrahão (2010); Ana Manuela López \& Aurora Lacueva (2007); Pedro & \\
Membiela (2002); Núria Monzonís-Martínez \& Marta Capllonch-Bujosa (2014); & \\
Vicente Navarro-Adelantado \& Francisco Jiménez-Jiménez (2012); Sandra & \\
Emilce Pérez-Rodríguez (2011); Sandra Quero-Ramones \& Leonel Madueño- & \\
Madueño (2006); Zonaida Ramírez \& Carmen Teresa Chacón (2007); Diana & \\
Marcela Rincón-Hernández (2013); Miriam Terán de Serrentino \& Lizabeth & \\
Pachano-Rivera (2009); Adriana Carolina Torres-Escobar (2014); César Vargas \& & \\
María Rosa Estupiñán (2012). &
\end{tabular}




\begin{tabular}{|c|c|c|}
\hline $\begin{array}{l}\text { Indagación autorreflexiva/ } \\
\text { carácter reflexivo/ } \\
\text { autorreflexión }\end{array}$ & $\begin{array}{l}\text { Amelia Barquín \& Nekane Plaza (2005); Juan Luis Cárdenas-Reyes, Gracia } \\
\text { Nacarí Lara-Guardia, Cristina Molina-Arias, Álvaro Moreno-Lucena \& Verónica } \\
\text { Morilla-Navarro (2014); Carme Carrillo-Aguilera \& Mercè Vilar i Monmany } \\
\text { (2009); Fernando Jesús Fariña-Pérez \& Juan José Sosa-Alonso (2011); Vicente } \\
\text { Navarro-Adelantado \& Francisco Jiménez-Jiménez (2012); José Antonio Pineda- } \\
\text { Alfonso (2013); Zonaida Ramírez \& Carmen Teresa Chacón (2007); Diana } \\
\text { Marcela Rincón-Hernández (2013); Deyse Ruiz \& Marianela García (2003); César } \\
\text { Vargas \& María Rosa Estupiñán (2012); Esperanza Vásquez-Arenas, Aurora } \\
\text { Becerra-Galindo \& Sandra Ximena Ibáñez-Córdoba (2014). }\end{array}$ & 11 \\
\hline $\begin{array}{l}\text { Vinculación investigador } \\
\text { con docentes, estudiantes, } \\
\text { comunidad para resolver } \\
\text { problemas educativos/ } \\
\text { conducida por los } \\
\text { involucrados }\end{array}$ & $\begin{array}{l}\text { Cinthia Baquedano \& Rebelín Echeverría (2013); Mónica P. Borjas \& Fátima } \\
\text { de la Peña-Leyva (2009); Carme Carrillo-Aguilera \& Mercè Vilar i Monmany } \\
\text { (2009); Francisco Javier Diego-Rasilla (2007); Sandra Milena García-González } \\
\text { (2014); Teresa Lleixà, Miguel Ángel Torralba \& Sergio Roberto Abrahão (2010); } \\
\text { Ana Manuela López \& Aurora Lacueva (2007); Vicente Navarro-Adelantado \& } \\
\text { Francisco Jiménez-Jiménez (2012); José A. Pareja-Fernández de la Reguera \& } \\
\text { Beatriz Pedrosa-Vico (2012); Helda Toloza, Norma Barletta \& Francisco Moreno } \\
\text { (2013); Patricia Valero-Alemán \& Freddy Mayora (2009). }\end{array}$ & 11 \\
\hline $\begin{array}{l}\text { Carácter emancipador desde } \\
\text { la perspectiva crítica }\end{array}$ & $\begin{array}{l}\text { María de Lourdes Acedo de Bueno (2004); Cecilia González-Terry (2011); Pedro } \\
\text { Membiela (2002); Zonaida Ramírez \& Carmen Teresa Chacón (2007); Darwin } \\
\text { Jesús Silva-Alayón (2010); Adriana Carolina Torres-Escobar (2014). }\end{array}$ & 6 \\
\hline $\begin{array}{l}\text { Comprensión de una } \\
\text { práctica y las situaciones en } \\
\text { las que se desarrolla }\end{array}$ & $\begin{array}{l}\text { Cinthia Baquedano \& Rebelín Echeverría (2013); Carme Carrillo-Aguilera \& } \\
\text { Mercè Vilar i Monmany (2009); Roberto Guillén-Correas \& Carlos Peñarrubia- } \\
\text { Lozano (2013); Ana María Mántica \& Ana Laura Carbó (2013); Deyse Ruiz \& } \\
\text { Marianela García (2003); Darwin Jesús Silva-Alayón (2010). }\end{array}$ & 6 \\
\hline $\begin{array}{l}\text { Construcción/producción } \\
\text { de conocimiento práctico/ } \\
\text { construcción de teoría } \\
\text { sustantiva }\end{array}$ & $\begin{array}{l}\text { Albert Casals, Mercè Vilar \& Jaume Ayats (2008); Josep Coral \& Teresa Lleixà- } \\
\text { Arribas (2013); Teresa Lleixà, Miguel Ángel Torralba \& Sergio Roberto Abrahão } \\
\text { (2010); César Vargas \& María Rosa Estupiñán (2012). }\end{array}$ & 4 \\
\hline $\begin{array}{l}\text { Desarrollo profesional } \\
\text { docente }\end{array}$ & $\begin{array}{l}\text { Javier Fernández-Río, Juan F. Medina-Gómez, Jacob Garro-García \& M. Pérez- } \\
\text { González (2001); Pedro Membiela (2002); Núria Monzonís-Martínez \& Marta } \\
\text { Capllonch-Bujosa (2014) }\end{array}$ & 3 \\
\hline $\begin{array}{l}\text { Docente investigador/romper } \\
\text { tradicional separación } \\
\text { investigador - investigados }\end{array}$ & $\begin{array}{l}\text { Juan Luis Cárdenas-Reyes, Gracia Nacarí Lara-Guardia, Cristina Molina-Arias, } \\
\text { Álvaro Moreno-Lucena \& Verónica Morilla-Navarro (2014); José Antonio } \\
\text { Pineda-Alfonso (2013); Zonaida Ramírez \& Carmen Teresa Chacón (2007). }\end{array}$ & 3 \\
\hline Otros, no aplica & $\begin{array}{l}\text { Mar Cepero-González, Ana García-Pérez \& Manuel López-López (2013); Adrián } \\
\text { Filiberto Contreras-Colmenares (2008); Carlos Andrés Hernández-Doria, } \\
\text { Marcela Georgina Gómez-Zermeño \& Maricela Balderas-Arredondo (2014); } \\
\text { María Manuela Jimeno (2000); Ana María Margallo-González (2009); María } \\
\text { Nieves Marín-Regalado (2012); María Ángeles Oriol-López (2009); Aurelia } \\
\text { Pimentel-Lorente (2000); Luis Santos-Rodríguez \& Javier Fernández-Río (2012); } \\
\text { José Augusto Trejo-Castro \& Noris Marcano (2013). }\end{array}$ & 10 \\
\hline
\end{tabular}

Fuente: elaboración propia

Nota: las categorías presentadas no son excluyentes,

pues algunos artículos se ubican en más de una categoría

No todos los artículos citan autores específicos para fundamentar el uso de la IA en educación. Algunos no citan autor alguno vinculado a la IA y fundamentan su opción metodológica con autores que exponen sobre la investigación cualitativa en general (16 artículos). Como se observa en la tabla 5, para fundamentar la IA, se basan en la perspectiva inglesa (Elliott, Stenhouse), o australiana (Carr, Kemmis o McTaggart). Hay, entonces, menos referencia a autores de Iberoamérica. 
Tabla 5

Autores y obras citadas para fundamentar la IA

\begin{tabular}{|c|c|}
\hline Autores y obras citadas & $\begin{array}{l}\text { Número de } \\
\text { artículos }\end{array}$ \\
\hline $\begin{array}{l}\text { John Elliott (1990). La investigación-acción en educación. Madrid: Morata. } \\
\text { John Elliott (1993). El cambio educativo desde la investigación-acción. } \\
\text { Madrid: Morata. }\end{array}$ & 20 \\
\hline $\begin{array}{l}\text { Antonio Latorre (2003). La investigación-acción. Conocer y cambiar la práctica } \\
\text { educativa. Barcelona: Graó. }\end{array}$ & 10 \\
\hline $\begin{array}{l}\text { Wilfred Carr \& Stephen Kemmis (1988). Teoría crítica de la enseñanza: la } \\
\text { investigación-acción en la formación del profesorado. Barcelona: Martínez Roca. }\end{array}$ & 9 \\
\hline James McKernan (1999). Investigación acción y curriculum. Madrid: Morata. & 9 \\
\hline $\begin{array}{l}\text { Stephen Kemmis \& Robin McTaggart (1992). Cómo planificar la investigación- } \\
\text { acción. Barcelona: Laertes. }\end{array}$ & 8 \\
\hline $\begin{array}{l}\text { Lawrence Stenhouse (1987). La investigación como base de la enseñanza. } \\
\text { Madrid: Morata. }\end{array}$ & 8 \\
\hline $\begin{array}{l}\text { Antonio Fraile-Aranda (1991). La investigación-acción: método de análisis } \\
\text { para una nueva educación física. Revista Interuniversitaria de Formación del } \\
\text { Profesorado, 10, 251-264. }\end{array}$ & 4 \\
\hline $\begin{array}{l}\text { Jean McNiff \& Jack Whitehead (2006). All You Need to Know about Action } \\
\text { Research. London: Sage. }\end{array}$ & 3 \\
\hline $\begin{array}{l}\text { Julia Blández-Ángel (1996). La investigación-acción: un reto para el profesorado. } \\
\text { Barcelona: INDE. }\end{array}$ & 2 \\
\hline $\begin{array}{l}\text { Paulo Freire (1969). La educación como práctica de la libertad. Montevideo: } \\
\text { Tierra Nueva. }\end{array}$ & 2 \\
\hline $\begin{array}{l}\text { Paloma López de Ceballos (1998). Un método para la investigación-acción } \\
\text { participativa. Madrid: Popular. }\end{array}$ & 2 \\
\hline $\begin{array}{l}\text { Raúl Rojas-Soriano (1999). Investigación-acción en el aula. Enseñanza-aprendizaje } \\
\text { de la metodología. México: Plaza y Valdés Editores. }\end{array}$ & 2 \\
\hline $\begin{array}{l}\text { Ezequiel Ander-Egg (2003). Repensando la investigación-acción-participativa. } \\
\text { Comentarios, críticas y sugerencias. Buenos Aires: Lumen. }\end{array}$ & 1 \\
\hline $\begin{array}{l}\text { N. Arellano (2004). ¿Cómo elaborar un proyecto de investigación acción? Parte I. } \\
\text { Colegio Belagua. }\end{array}$ & 1 \\
\hline $\begin{array}{l}\text { Christine K. Bennett (1994). Promoting Teacher Reflection through Action } \\
\text { Research: What Do Teachers Think? Journal of Staff Development, } 15 \text { (1), 34-38. }\end{array}$ & 1 \\
\hline $\begin{array}{l}\text { Juan M. Escudero-Muñoz (1987). La investigación-acción en el panorama actual } \\
\text { de la investigación educativa: algunas tendencias. Revista de investigación e } \\
\text { innovación educativa, 3, 5-39. }\end{array}$ & 1 \\
\hline $\begin{array}{l}\text { Mohammad Anisur Rahman \& Orlando Fals-Borda (1989). La situación actual y las } \\
\text { perspectivas de IAP en el mundo. En María Cristina Salazar (ed.). La investigación } \\
\text { acción participativa, 205-223. Bogotá: Cooperativa Editorial Magisterio. }\end{array}$ & 1 \\
\hline $\begin{array}{l}\text { Gabriel Goyette \& Michelle Lessard-Hébert (1998). La investigación-acción. } \\
\text { Funciones, fundamentos e instrumentación. Barcelona: Laertes. }\end{array}$ & 1 \\
\hline $\begin{array}{l}\text { E. Alana James, Margaret T. Milenkiewicz \& Alan Bucknam (2008). Participatory } \\
\text { Action Research for Education Leadership: Using Data-Driven Decision Making to } \\
\text { Improve Schools. Los Ángeles: Sage. }\end{array}$ & 1 \\
\hline $\begin{array}{l}\text { Kurt Lewin (1946). Action Research and Minority Problems. Journal of Social Issues, } \\
2 \text { (4), 34-46. }\end{array}$ & 1 \\
\hline $\begin{array}{l}\text { Sharon Nodie Oja \& Lisa Smulyan (1989). Collaborative Action Research: A } \\
\text { Developmental Approach. Lewes, East Sussex: Falmer Press. }\end{array}$ & 1 \\
\hline $\begin{array}{l}\text { Richard Sagor (1992). How to Conduct Collaborative Action Research. Alexandria, } \\
\text { Virginia: Association for Supervision and Curriculum Development, ASCD. }\end{array}$ & 1 \\
\hline
\end{tabular}

Fuente: elaboración propia

Nota: muestra las veces que se cita un autor/obra, considerando que hay artículos que citan más de uno. 
La investigación-acción en los contextos de aula en Iberoamérica

Las experiencias de IA reportadas en los artículos corresponden en especial a aquellas desarrolladas en aulas de escuelas de España (28 artículos) y Venezuela (12 artículos); le siguen Colombia (7 artículos), Chile y México (2 artículos cada uno), y Cuba, Argentina y Bolivia (1 artículo cada uno). En tres artículos, no se identifica la ciudad donde está ubicada la escuela.

El 54\% de ellos describe experiencias en aulas de educación secundaria y el $46 \%$, en aulas de educación primaria con grupos de niños de distintas edades. Los estudios se desarrollan en las temáticas de educación física (13 artículos), y lenguaje o literatura (8 artículos) (tabla 6). En su mayoría, las experiencias de IA se crean en aquellas áreas del currículo escolar como la educación física, educación musical, temas transversales, inglés o ciencias sociales, que no suelen ser evaluadas en las mediciones internacionales o nacionales, que mayormente se focalizan en matemática y comprensión lectora. Con ello, parece que la IA, al enfrentar al docente a innovaciones puestas en marcha en sus clases, prefiere hacerlo en espacios (grados y áreas) que no exijan dar cuenta de resultados de aprendizaje o de eficiencia del sistema de formación. Al respecto, por ejemplo, Francisco Javier Diego-Rasilla (2007) señala que opta por estudiar con niveles inferiores de la secundaria porque no están condicionados por las pruebas de acceso a la universidad. A esta problemática se refiere de modo similar Nelofer Halai (2012), cuando describe las tensiones entre los sistemas de evaluación y la innovación en la IA.

Tabla 6

Temáticas abordadas en la IA

\begin{tabular}{l|c|c}
\hline Temáticas & $\begin{array}{l}\text { Número de } \\
\text { artículos }\end{array}$ & (\%) \\
\hline Educación física & 13 & 22 \\
\hline Lenguaje/lengua/literatura & 8 & 14 \\
\hline Educación musical & 7 & 12 \\
\hline Otros transversales: salud, TIC, proyectos & 7 & 12 \\
\hline Ciencias naturales/educación ambiental & 6 & 11 \\
\hline Matemática & 4 & 7 \\
\hline Ciencias/química/física & 4 & 7 \\
\hline Convivencia & 4 & 7 \\
\hline Ciencias sociales/Historia & 3 & 5 \\
\hline Inglés & 1 & 3 \\
\hline \hline
\end{tabular}

Fuente: elaboración propia

Kathryn Herr y Gary L. Anderson (2015) reconocen un continuum de cinco posiciones en que se ubica el investigador que desarrolla IA, que van desde una posición interna (insider, que estudia su propia práctica) hasta una externa (outsider, que estudia a quienes realizan la práctica). Cuando la investigación es realizada por el mismo maestro-investigador, se espera que los resultados de la IA se escriban narrativamente en primera persona (McNiff, 2014; Herr \& Anderson, 2015; Reason \& Bradbury, 2001). Como indicamos antes, hay diez artículos escritos por los mismos maestros (insider) que desarrollan la IA (9 de modo individual y 1 en equipo). De ellos, 
solo tres son escritos en primera persona para expresar el proceso vivido y sus reflexiones de modo narrativo. Los otros siete utilizan las normas formales de redacción de los artículos académicos en español: tercera persona plural o en impersonal, para referirse a la investigación como "algo externo" a ellos, por tanto, actúan como ousiders de la IA.

En los cinco casos de IA escritos por maestros con investigador afiliado a una universidad, del mismo modo se observa el uso del plural o el impersonal. Un solo caso (Fariña-Pérez \& Sosa-Alonso, 2011) narra "nuestro proyecto" y el académico cumple el rol de "compañero orientador", a modo del amigo crítico de la IA (Elliott, 1993; McNiff, 2014).

En los artículos escritos por autores vinculados a una universidad, se refieren a los maestros como participantes o sujetos de estudio. Una de las características de la IA es que los participantes sean considerados como coinvestigadores (Rowell, Polush, Riel \& Bruewer, 2015). Solo tres artículos lo hacen.

Ello revela que, en los artículos de IA, los maestros - principales protagonistas de las acciones que se desarrollan en el aula- no siempre son los protagonistas de la investigación y la difusión de sus resultados; por otro lado, sus narrativas - cuando las hay — son mediadas por los investigadores (académicos universitarios), quienes las describen e interpretan.

\section{Aportes y limitaciones de la IA}

Más allá de los resultados y las conclusiones que cada uno de los estudios revela relacionados con la mejora de los procesos y la calidad de los aprendizajes de los estudiantes, se destacan otros aportes vinculados con la aplicación de la IA en las aulas. Si bien echamos de menos que no todos los artículos reflexionan sobre ello - aspecto clave por ser el principal aporte de la IA-, quienes lo hacen destacan: los cambios en la práctica docente o en las concepciones y creencias de los profesores; la posibilidad de reflexionar sobre sus propios problemas y buscar alternativas innovadoras para superarlos y seguir aprendiendo; el trabajo colaborativo entre maestros, o entre investigadores externos y maestros; la toma de decisiones informada y más crítica; y un espacio para generar innovaciones y la posibilidad de aprender de la práctica (tabla 7). Estos aportes han sido también reconocidos por los autores que han realizado revisiones de la literatura sobre IA.

Tabla 7

Aportes de la IA

\begin{tabular}{|c|c|}
\hline Aportes de la IA & Evidencia (algunas citas) \\
\hline Reflexión de los docentes & $\begin{array}{l}\text { "El clima de libertad en el que se desarrolló esta experiencia, permitió que la maestra } \\
\text { reflexionara acerca de sus retos y compromisos en el desempeño de su profesión" } \\
\text { (Ruiz \& García, 2003, p. 327). } \\
\text { "...el trabajo con las maestras permitió reflexionar acerca de diferentes ideas como resultado } \\
\text { del proceso colectivo" (Baquedano \& Echeverría, 2013, p. 156). } \\
\text { "Cuando un profesional es capaz de integrar conceptos nuevos y esclarecedores, puede } \\
\text { comprender la realidad cabalmente, relacionando la teoría con la práctica cuando reflexiona } \\
\text { sobre su quehacer cotidiano, ya que puede identificar sus fortalezas y mejorar sus debilidades" } \\
\text { (Rosas, Jiménez \& Ulloa, 2005, p. 76). } \\
\text { "... se comprueba que el hecho de involucrarse en dinámicas de investigación y mejora, en } \\
\text { y sobre la propia práctica, conduce a la adopción del rol reflexivo que se reclama para los } \\
\text { profesionales de la educación" (Fariña-Pérez \& Sosa-Alonso, 2011, pp. 114-115). }\end{array}$ \\
\hline
\end{tabular}


Cambios de los docentes, concepciones de la práctica o de las

"Es de destacar el interés de la profesora en la experiencia y en continuarla; gradualmente desarrolló sentido de criticidad hacia su práctica pedagógica y un cambio de actitud al darse cuenta de que ella misma podía aportar significativamente al proceso" (Toloza, Barletta \& Moreno, 2013, pp. 51-52).

"...permitió construir una visión más crítica y creativa de la práctica pedagógica de las docentes investigadoras" (Vásquez-Arenas, Becerra-Galindo \& Ibáñez-Córdoba, 2014, p. 85).

"...ampliaron sus conocimientos, mejoraron sus habilidades profesionales — al ser agentes activos en el diseño, implementación y evaluación de un proyecto curricular-, adquirieron nuevos roles al actuar no solo como profesores sino también como investigadores y lograron prestigio profesional al integrarse en la comunidad académica de innovación e investigación educativa" (Membiela, 2002, p. 448).

"...la experiencia ha supuesto para el docente un replanteamiento en las creencias y convicciones personales (...) sobre el modo de plantear y conducir la clase" (Menéndez-Santurio \& Fernández-Río, 2014, p. 38).

"...constituyó una experiencia innovadora de desarrollo profesional por parte de la docente-investigadora (...) desde una perspectiva reconstruccionista apoyada en procesos reflexivos y en colaboración con la asesora externa, reinterpretó sus teorías, supuestos y creencias sobre su práctica pedagógica" (Ramírez \& Chacón, 2007, p. 304).

"descubrí elementos valiosos para tener en cuenta en los procesos investigativos pero también descubrí mis debilidades, en las que debo enfocarme para mejorar mis prácticas y especialmente mi reflexión sobre mis desempeños en el aula" (Rincón-Hernández,

2013, p. 669)

"...propiciar el aprendizaje comprensivo y creativo, articulando las viejas teorías personales con las significaciones académicas, las cuales permiten construir nuevas interpretaciones aplicables en el mundo escolar y cotidiano" (Hernández-Gil, 2007, p. 32).

Útil para la toma de decisiones

"En mi práctica educativa este estudio me brindó mayores herramientas para tomar decisiones argumentadas y enriquecer mi práctica en el aula de clase. Actualmente me cuestiono en mayor profundidad aspectos como: ¿cuál o cuáles son las habilidades o competencias que quiero desarrollar con mis estudiantes en x grado? y ¿cuáles son los conocimientos esenciales del grado en el que se encuentran? (Rincón-Hernández, 2013, p. 668).

"La experiencia de observar su práctica pedagógica en los videos de las clases y reflexionar con los investigadores demostró ser muy útil para la toma de decisiones y del desarrollo de la conciencia crítica de parte de la docente" (Toloza, Barletta \& Moreno, 2013, p. 52).

Compartir/trabajo colaborativo "una aventura pedagógica que enriquece el proceso educativo al compartir temores, inquietudes, vivencias y fortalezas con cada uno de los miembros que constituyen la comunidad educativa" (Borjas \& De la Peña-Leyva, 2009, p. 34)

"...el trabajo en equipo ha permitido un intercambio de opiniones, dudas y sugerencias muy enriquecedor y motivador, (...) potenciando así el trabajo en equipo en la planificación de la tarea educativa (Diego-Rasilla, 2007, p. 15)

"Tanto los acuerdos entre sus diferentes miembros para planificar, desarrollar y evaluar juntos procesos de enseñanza-aprendizaje, (...) están orientados a conseguir estos logros (Vaca, 2010, p. 306).

"En primer lugar, la importancia y la facilidad con que se intercambiaron los roles. En segundo lugar, la riqueza que aportaron los debates dentro del equipo antes, durante y después de la aplicación. Y, por último, la irradiación que tuvo el trabajo conjunto más allá del grupo-clase en el que se incidió" (Casals, Vilar \& Ayats, 2008, pp. 14-15).

\begin{tabular}{l|l}
$\begin{array}{l}\text { Espacio para generar } \\
\text { innovaciones }\end{array}$ & $\begin{array}{l}\text { "Esta experiencia constituyó un espacio para inventar estrategias, juegos y recursos para el } \\
\text { aprendizaje de la matemática" (Ruiz \& García, 2003, p. 327). } \\
\text { "...permitió trascender la consideración de lo dado para avanzar hacia el ensayo de cambios, } \\
\text { estudiados con autenticidad" (López \& Lacueva, 2007, p. 115). }\end{array}$ \\
\hline $\begin{array}{l}\text { Aprender sobre } \\
\text { la práctica }\end{array}$ & $\begin{array}{l}\text { "...esta investigación nos ha servido, tanto a los profesores universitarios como a los maestros } \\
\text { que han participado, para aprender sobre la práctica didáctica" (Lleixà, Torralba \& Abrahão, } \\
2010, \text { p. 47). }\end{array}$ \\
\hline \hline
\end{tabular}

Fuente: elaboración propia 
De otro lado, las mayores dificultades reportadas en los artículos son las siguientes: el poco tiempo disponible para el desarrollo de la IA; las resistencias al cambio traducidas en miedo o temor frente a lo nuevo o la incertidumbre de los resultados; las condiciones institucionales, como espacio, materiales y, especialmente, las exigencias de la escuela (logro de objetivos y resultados, cumplimiento de normativas) que impiden innovar; el compromiso de la dirección y del profesorado; y la imposibilidad de ofrecer continuidad al proyecto de IA o generalizar los resultados a otros contextos.

Tabla 8

Limitaciones de la IA

\begin{tabular}{|c|c|}
\hline Aportes de la IA & Evidencia (algunas citas) \\
\hline $\begin{array}{l}\text { Tiempo para } \\
\text { desarrollar la IA }\end{array}$ & $\begin{array}{l}\text { "La necesidad de sumar esfuerzos para desarrollar otros aspectos de la vida colegial ha limitado } \\
\text { considerablemente el tiempo disponible para esta investigación" (Diego-Rasilla, 2007, p. 114). } \\
\text { "...la limitación del tiempo susceptible de destinarse al desarrollo y a la innovación educativa } \\
\text { emerge claramente como un factor limitante para una mayor implicación de los docentes en } \\
\text { su desarrollo profesional. Dada la actual organización del sistema escolar, es difícil para un } \\
\text { maestro poder compatibilizar la triple vertiente docencia-formación-investigación" (Casals, Vilar } \\
\text { \& Ayats, 2008, p. 15). } \\
\text { "Desde el punto de vista de las docentes son la falta de tiempo y de personal especializado en el } \\
\text { área los principales factores que dificultan el dar continuidad a dichas acciones" (Baquedano \& } \\
\text { Echeverría, 2013, p. 157). } \\
\text { "...el poco tiempo disponible para desempeñar este tipo de metodología en el aula, lo cual } \\
\text { pensamos que ha podido dificultar el proceso de reflexión y asimilación que requería este } \\
\text { tipo de investigación (Cárdenas-Reyes, Lara-Guardia, Molina-Arias, Moreno-Lucena \& Morilla- } \\
\text { Navarro, 2014, p. 134). } \\
\text { "...debido al limitado tiempo del que se ha dispuesto en el proceso de este proyecto, } \\
\text { los resultados no son concluyentes" (Vásquez-Arenas, Becerra-Galindo \& Ibáñez-Córdoba, } \\
\text { 2014, p. 219). } \\
\text { "...Se ha planteado una sola cuestión acorde tanto a las limitaciones temporales existentes } \\
\text { (nos encontrábamos restando tiempo a otra materia)..." (Menéndez-Santurio \& Fernández-Río, } \\
2014, \text { p. 38). }\end{array}$ \\
\hline $\begin{array}{l}\text { Condiciones del aula, } \\
\text { la escuela o el sistema } \\
\text { educativo }\end{array}$ & $\begin{array}{l}\text { "...la necesidad de materiales e instalaciones específicos o la limitación dada por el propio } \\
\text { horario de la asignatura" (Guillén \& Peñarrubia, 2013, p. 23). } \\
\text { "...la falta de materiales pertinentes (...) la inversión enorme de tiempo para poder crear } \\
\text { materiales que tengan cierta relevancia didáctica, los requisitos técnicos necesarios, los } \\
\text { cuales condicionan enormemente la creación de proyectos de este tipo, al menos con cierta } \\
\text { periodicidad" (Palazón-Herrera, 2013, pp. 62-63). } \\
\text { "Aunque el manejo de las herramientas en general no fue complicada [sic], sí que resultaba } \\
\text { difícil compaginarlo e integrarlo en el trabajo diario" (Fernández-Olaskoaga, Correa-Gorospe \& } \\
\text { Ochoa-Aizpurua Agirre, 2013, p. 255). } \\
\text { "Fue proyectada como un cambio reflexivo de la práctica y, naturalmente, tiene sus limitaciones } \\
\text { debido a que todo este proceso se encuentra inmerso en el conjunto de actividades que se } \\
\text { mantienen en el centro, algunas de las cuales condicionan el desarrollo de esta investigación" } \\
\text { (Diego-Rasilla, } 2007, \text { p. } 111 \text { ). } \\
\text { "...condicionantes externos de la tarea del profesor que hacen que los elementos de gestión del } \\
\text { aula se enmarquen en unos márgenes bastante estrechos, delimitados por la propia dinámica } \\
\text { del centro y por la definición «social» que se hace de la tarea que debe desarrollar un profesor } \\
\text { (...) los condicionamientos reales que imponen los centros, los objetivos de sus planes de } \\
\text { estudio y la obligatoriedad de evaluarlos. (...) Los contenidos vienen condicionados por ley y } \\
\text { permiten poco espacio para la innovación" (Perseguer, 2012, p. 277). }\end{array}$ \\
\hline
\end{tabular}


Resistencias/miedos/ incertidumbre frente al cambio "...resistencias al cambio: las ligadas a la personalidad (como la preferencia por la estabilidad y el miedo a lo desconocido), las relacionadas con el sistema social (como la conformidad con las normas y el carácter sagrado de ciertas prácticas); además de las vinculadas al modo de implantación del cambio (como son los tiempos y los medios estratégicos que se propongan para lograrlo)" (Baquedano \& Echeverría, 2013, p. 157).

"...temor al cambio, la falta de incentivos, la inercia institucional, la poca resistencia a la incertidumbre, el temor al fracaso y la inseguridad por falta de preparación" (Toloza, Barletta \& Moreno, 2013, p. 53).

"...sobreponerse a la fase de duda de cómo se debía trabajar por proyectos. Consideramos que este es un claro ejemplo del miedo escénico que provoca lo novedoso y que la forma de controlarlo es teniéndolo todo bien atado" (Fernández-Olaskoaga, Correa-Gorospe \& OchoaAizpurua Agirre, 2013, p. 255).

"...en los momentos iniciales en los que se empieza a fraguar la propuesta de cambio, la incertidumbre, la inseguridad acerca de si es posible o no desarrollar cambios de calado en un contexto que no se los plantea a nivel global (...) condujo a una encrucijada... (Fariña-Pérez \& Sosa-Alonso, 2011, p. 115).

Dificultad para impactar o generalizar resultados "...la mayoría de las acciones se lograron desarrollar en un plazo específico, pero sin integrarse o impactar a nivel curricular" (Baquedano \& Echeverría, 2013, p. 157).

"...se trata de un proyecto realizado solamente en una escuela primaria, por lo que no existen condiciones para generalizar los resultados" (Ríos-Cortázar, Gasca-García, Franco-Martínez \& Tolentino-Mayo, 2014, pp. S136-S137).

"...esta intervención tiene un impacto limitado por haber sido trabajada solo en un aula" (Toloza, Barletta \& Moreno, 2013, p. 53).

“Otra limitación inherente a cualquier investigación-acción es su particularismo. No obstante, el proceso desarrollado por un grupo colaborativo suele producir resultados que, en determinadas circunstancias, pueden ser válidos y sugerentes para la constitución de otros grupos en el propio centro -implicando nuevas áreas de conocimiento- e incluso para otros grupos en otros contextos" (Casals, Vilar \& Ayats, 2008, p. 15).

Compromiso institucional y del profesorado

"... se constata la dificultad que implica el hacerlo [los procesos de mejora desplegados] en contextos que no asumen estos cambios desde una dimensión institucional" (Fariña-Pérez \& Sosa-Alonso, 2011, p. 115).

"... algunos habían abandonado a mitad de camino, lo que dificultó el trabajo colaborativo y de consenso acordado en las primeras reuniones" (Pareja-Fernández de la Reguera \& Pedrosa-Vico, 2012, p. 482).

"la falta de colaboración entre el profesorado, manifestando que tan solo un reducido grupo ha sido capaz de llevar a cabo lo acordado y trabajar según lo esperado, mediante el consenso, la ayuda mutua y el trabajo en equipo" (Pareja-Fernández de la Reguera \& Pedrosa-Vico,

2012, p. 487)

"...creemos que los resultados hubieran sido aún más positivos en todos los grupos si se hubiera contado con un mayor soporte de todo el profesorado, ya que, aunque no era lo esperado, solo las tutoras de quinto fueron las que acabaron siendo el motor del proceso (Monzonís-Martínez \& Capllonch-Bujosa, 2014, p. 184).

Fuente: elaboración propia

\section{Discusión y conclusiones}

Esta primera exploración de los artículos que usan la IA en aulas de educación básica en Iberoamérica muestra que ella se justifica desde la innovación, el cambio y la mejora de la práctica pedagógica de los maestros, y que se circunscribe a un enfoque más interpretativo (McKernan, 1999) vinculado al desarrollo profesional. El carácter político y ético — característico del enfoque sociocrítico y de los inicios de la IA en Latinoaméricaque busca la emancipación y la transformación no solo de la práctica, sino de las condiciones sociales en las que se generan, está menos presente en 
las experiencias de IA en aulas y en las reflexiones de los maestros recogidas en los artículos revisados. Se trataría entonces, principalmente de una IA pedagógica (Restrepo-Gómez, 2004), y no de una IA participativa en el marco de lo propuesto por Paulo Freire y Orlando Fals-Borda, que trasciende el aula. El énfasis encontrado en la IA pedagógica se puede atribuir a que la IA más crítica se realiza en las aulas, pero está "invisible" en las publicaciones académicas (Flores-Kastanis, Montoya-Vargas \& Suárez, 2009), aunque su comprobación sería objeto de otro estudio; y a las políticas educativas que en los últimos años han girado hacia la escuela y al desarrollo profesional del maestro para mejorar la calidad de los aprendizajes de los estudiantes.

Por otro lado, la revisión de la literatura revela que hay áreas temáticas o asignaturas preferidas para emprender procesos de IA e innovación en las aulas. De hecho, son aquellas en los que no se suele demandar la rendición de cuentas de los aprendizajes de los estudiantes: la educación física, la educación musical, la educación ambiental, el desarrollo de la convivencia, entre otras. La exigencia en el cumplimiento de los contenidos curriculares vinculados con la matemática y la comunicación o los vinculados al éxito académico para el ingreso a la Universidad; y la tendencia a la evaluación de la calidad de los aprendizajes en el marco de los sistemas de medición y evaluación nacionales e internacionales parecen ser algunas de las razones por las que no se desarrolla IA en estas asignaturas. Las exigencias de los sistema de evaluación pueden convertirse en barreras para realizar IA (Diego-Rasilla, 2007; Halai, 2012) en cuanto ella supone espacios y tiempos de reflexión y acción en el aula centrados en los procesos.

Un tema que resulta problemático, y que sin ánimos de ser exhaustivos, puede ser objeto de mayor profundización en futuros estudios, se refiere a la IA y el lugar del maestro-investigador, en la investigación misma y en su difusión. La revisión de los artículos muestra que los docentes se involucran en una dinámica lineal (diagnóstico-innovación-evaluación) propuesta por outsiders (Herr \& Anderson, 2015): docentes universitarios que intervienen con proyectos de IA en una o varias aulas de clase comprometiendo a los maestros (trabajando colaborativamente) en el desarrollo de una innovación en un contenido específico. Frente a ello, ihasta qué punto se logra empoderar a los maestros como maestros-investigadores si se mantiene la división investigación (académico-universitario)/acción (práctico-maestro)? Ello evidencia que las relaciones entre académicos y maestros no ha cambiado, y refleja el poder de los investigadores sobre los prácticos en la generación de conocimiento. Los maestros siguen siendo participantes en la investigación y no coinvestigadores de la misma. Desarrollar IA es la oportunidad para atribuir protagonismo a los maestros en la investigación y en la escritura de la IA. Esta tarea no es fácil, pues supone construir una identidad docente distinta que involucra capacidades para hacer investigación sobre su propia práctica, y por las dificultades para conciliar ambos roles en el aula: práctico e investigador (Halai, 2012).

De otro lado, ¿qué hace diferente la IA de una investigación cuasiexperimental, o de la validación de una experiencia de innovación o de la investigación aplicada? La reflexión y la narración sobre la acción constituyen elementos diferenciadores de la IA en relación con otros métodos de investigación. El mero hecho de una intervención o el desarrollo de una innovación resultan limitados para comprender los alcances y riqueza de este método de investigación. Si bien en este estudio no se ha analizado sistemáticamente el contenido de la reflexión que se expresa en los artículos, se entiende que ella es el análisis retrospectivo de la acción 
para ganar conocimiento de la experiencia (Schön, 1998) y transformar la acción (Rowell, Polush, Riel \& Bruewer, 2015) durante la IA en una espiral cíclica. Ello supone un tono narrativo en primera persona de quien o quienes viven la experiencia de IA, que — como se ha analizado- aparece en muy pocos artículos.

Esto último lleva a otro tema de discusión: la legitimidad de la IA para ser difundida en artículos de revistas académicas o en tesis de posgrado, problemática destacada en la revisión de Michelle Vaughan y Gail Burnaford (2016). Los resultados muestran que los estudios han sido aceptados en revistas, en especial en las vinculadas con innovaciones en la didáctica. Sin embargo, al igual que en otros países, hacer y publicar IA en educación puede crecer en los últimos años en Iberoamérica y, con ello, el reto de crear criterios de calidad rigurosos para este tipo de estudios (ZuberSkerritt \& Fletcher, 2007).

Esta revisión de la literatura ha pretendido ser una aproximación sobre qué se ha producido sobre IA en aulas de Iberoamérica, con la limitación de no haber recogido lo producido en Brasil. Los resultados sugieren recuperar una perspectiva sociocrítica de la IA en Iberoamérica que no solo se oriente a la mejora de la práctica del maestro sobre su enseñanza, sino que la trascienda como profesional reflexivo, empoderado en su rol social y transformador. Para ello se necesita potenciar el desarrollo, escritura y difusión de experiencias de IA realizadas por docentes, que como se ha señalado y se muestra en esta revisión, no siempre son difundidas en artículos académicos. Ello permitirá no solo legitimar la IA como una forma de hacer investigación por maestros, sino de dar autonomía y profesionalidad al docente.

También quedan temas para seguir profundizando, por ejemplo, los criterios de calidad de la IA; la escritura de un proceso que no es lineal y que debe ser capaz de expresar la complejidad del proceso cíclico; los principios éticos en la IA en la relación investigador-maestro; $y$, en especial, el reto de empoderar a los maestros en la escritura y difusión de la IA, maestros que individualmente, o en equipo, o con investigadores académicos externos (como colaboradores o amigos críticos), o como coinvestigadores, sean quienes narren en primera persona sus reflexiones sobre la mejora en sus aulas y la transformación de sus prácticas.

\section{Sobre la autora}

Carmen del Pilar Díaz-Bazo es doctora en ciencias de la educación, Universidad Católica de Lovaina - La Nueva (Bélgica). Profesora principal del Departamento Académico de Educación de la Pontificia Universidad Católica del Perú, PUCP. Sus investigaciones y publicaciones se vinculan con la formación en investigación, en especial en el posgrado, la investigación-acción, y la gestión escolar.

\section{Referencias}

Acedo de Bueno, María de Lourdes (2004). Plan de enseñanza. Historia para el historiador principiante para Educación Media. Anales de la Universidad Metropolitana, 4 (1), 33-49. Disponible en: https://dial net.unirioja.es/descarga/articulo/4003722.pdf

Baquedano, Cinthia \& Echeverría, Rebelín (2013). Competencias psicosociales para la convivencia escolar libre de violencia: experiencia en una primaria pública de Mérida, Yucatán, México. Psicoperspectivas, 12 (1), 139-160. Disponible en: http://www.psicoperspectivas.cl/in dex.php/psicoperspectivas/article/viewFile/210/251 
Barquín, Amelia \& Plaza, Nekane (2005). La luciérnaga que era... ¿diferente? Un aula "multicultural" en Guipúzcoa: convivencia y conflictos entre los alumnos e intervención de las maestras. Revista de Educación, 338, 377-406. Disponible en: http://www.revistaeducacion.mec. es/re338_20.htm

Blández-Ángel, Julia (1996). La investigación-acción: un reto para el profesorado. Guía práctica para grupos de trabajo, seminarios y equipos de investigación. Barcelona: INDE.

Booth, Andrew; Papaioannou, Diana \& Sutton, Anthea (2012). Systematic Approaches to a Successful Literature Review. London: Sage. Disponible en: https://www.researchgate.net/profile/ Andrew_Booth/publication/235930866_Syste matic_Approaches_to_a_Successful_Literatu re_Review/links/55f89fae08aec948c4837066/ Systematic-Approaches-to-a-Successful-Litera ture-Review.pdf

Borjas, Mónica P. \& Peña-Leyva, Fátima de la (2009). Desarrollo de habilidades de pensamiento creativo en el área de ciencias naturales y educación ambiental. Zona Próxima, 10, 12-35. Disponible en: http://rcientificas.uninorte.edu.co/index. php/zona/article/viewArticle/1655/4645

Cárdenas-Reyes, Juan Luis; Lara-Guardia, Gracia Nacarí; Molina-Arias, Cristina; Moreno-Lucena, Álvaro \& Morilla-Navarro, Verónica (2014). Mejora del clima de convivencia en el aula mediante una metodología de investigación-acción. Revista Electrónica de Investigación y Docencia Creativa de la Universidad de Granada, ReiDoCrea, 3, 127141. Disponible en: http://digibug.ugr.es/bits tream/10481/32268/1/ReiDoCrea-Vol.3-Art.19Cardenas-Lara-Molina-Moreno-Morilla.pdf

Carr, Wilfred \& Kemmis, Stephen (1988). Teoría crítica de la enseñanza: la investigación-acción en la formación del profesorado. Barcelona: Martínez Roca.

Carrillo-Aguilera, Carme \& Vilar i Monmany, Mercè (2009). El conjunto instrumental Orff como dinamizador de la motivación en alumnos de educación secundaria. Revista Electrónica de LEEME (Lista Electrónica Europea de Música en la Educación), 23, 1-14. Disponible en: http://musica. rediris.es/leeme/revista/carrillo\&vilar09.pdf

Casals, Albert; Vilar, Mercè \& Ayats, Jaume (2008). La investigación-acción colaborativa. Reflexiones metodológicas a partir de su aplicación en un proyecto de música y lengua. Revista Electrónica Complutense de Investigación en Educación Musical, 5 (4), 1-16. Disponible en: http://pendiente demigracion.ucm.es/info/reciem/v5n4.pdf
Cepero-González, Mar; García-Pérez, Ana \& López-López, Manuel (2013). Diseño de un programa de intervención bilingüe para el área de educación física basado en la competencia digital. Porta Linguarum. Revista Internacional de Didáctica de las Lenguas Extranjeras, 19, 257-273. Disponible en: https://dialnet.unirioja.es/descarga/articu lo/4594836.pdf

Conde-Núñez, María del Carmen; Sánchez-Cepeda, J. Samuel \& Corrales-Vázquez, José María (2009). Conectando la investigación y la acción. Aportaciones desde una experiencia en torno a ecoauditorías escolares. Revista Electrónica de Enseñanza de las Ciencias, 8 (1), 23-44. Disponible en: http://reec.uvigo.es/volumenes/volumen8/ ART2_Vol8_N1.pdf

Contreras-Colmenares, Adrián Filiberto (2008). La coetaneidad en el proceso de mediación y aprendizaje de la lectura. Acción Pedagógica, 17 (1), 56-67. Disponible en: https://dialnet.unirioja.es/ servlet/articulo?codigo $=2967447$

Coral, Josep \& Lleixà-Arribas, Teresa (2013). Las tareas en el aprendizaje integrado de educación física y lengua extranjera (AICLE). Determinación de las características de las tareas mediante el análisis del diario de clase. Retos. Nuevas Tendencias en Educación Física, Deporte y Recreación, 24, 7984. Disponible en: https://dialnet.unirioja.es/ser vlet/articulo?codigo $=4473846$

Dick, Bob (2006). Action Research Literature 20042006. Themes and Trends. Action Research, 4 (4), 439-458. London: Sage.

Dick, Bob (2009). Action Research Literature 20062008. Themes and Trends. Action Research, 7 (4), 423-441. London: Sage.

Dick, B. (2011). Action Research Literature 2008-2010. Themes and trends. Action Research, 9 (2), 122143. London: Sage.

Diego-Rasilla, Francisco Javier (2007). La investigaciónacción como medio para innovar en las ciencias experimentales. Pulso, 30, 103-118. Disponible en: https://dialnet.unirioja.es/descarga/articu lo/2498251.pdf

Elliott, John (1990). La investigación-acción en educación. Madrid: Morata.

Elliott, John (1993). El cambio educativo desde la investigación-acción. Madrid, La Coruña: Ediciones Morata, Fundación Paideia.

Fariña-Pérez, Fernando Jesús \& Sosa-Alonso, Juan José (2011). Reflexión y mejora en la práctica docente: narración de una experiencia en el área de tecnología. Qurriculum, Revista de Teoría, Investigación y Práctica Educativa, 24, 85-116. Disponible en: http://revistaq.webs.ull.es/ANTERIORES/nu mero24/farina.pdf 
Fernández-Olaskoaga, Lorea; Correa-Gorospe, José Miguel \& Ochoa-Aizpurua Agirre, Begoña (2013). Eskola 2.0: un curso completado. Tiempo de evaluación. Revista Fuentes, 13, 239-262. Disponible en: https://idus.us.es/xmlui/hand le/11441/33702

Fernández-Río, Javier; Medina-Gómez, Juan F.; Garro-García, Jacob \& Pérez-González, M. (2001). Un ejemplo de investigación-acción aplicado al bloque de contenidos de condición física en enseñanza secundaria. Revista Internacional de Medicina y Ciencias de la Actividad Física y del Deporte, 1 (2), 84-99. http://cdeporte.rediris.es/ revista/revista2/artcondfis.pdf

Flores-Kastanis, Eduardo; Montoya-Vargas, Juny \& Suárez, Daniel H. (2009). Investigación-acción participativa en la educación latinoamericana. Un mapa de otra parte del mundo. Revista Mexicana de Investigación Educativa, 14 (40), 289308. Disponible en: http://www.redalyc.org/ pdf/140/14004013.pdf

Fouché, Christa B. \& Chubb, Laura A. (2016). Action Researchers Encountering Ethical Review: A Literature Synthesis on Challenges and Strategies. Educational Action Research, 25 (1), 23-34. DOI: 10.1080/09650792.2015.1128956

Freire, Paulo (1969). La educación como práctica de la libertad. Montevideo: Tierra Nueva.

García-González, Sandra Milena (2014). Rol mediador docente en la comprensión de textos. Enunciación, 19 (2), 252-267. Disponible en: https://dial net.unirioja.es/descarga/articulo/5016208.pdf

Gibbs, Paul; Cartney, Patricia; Wilkinson, Kate; Parkinson, John; Cunningham, Sheila; James-Reynolds, Carl; Zoubir, Tarek; Brown, Venetia; Barter, Phil; Sumner, Pauline; MacDonald, Angus; Dayananda, Asanka \& Pitt, Alexandra (2017). Literature Review on the Use of Action Research in Higher Education. Educational Action Research, 25 (1), 3-22. DOI: 10.1080/09650792.2015.1124046

González-Terry, Cecilia (2011). Metodología de orientación flexible para favorecer aprendizaje significativo en las clases de educación física: propuesta desde el enfoque problematizador. Acciónmotriz, 7, 5-21. Disponible en: http://www.mdc.ul pgc.es/cdm/ref/collection/amotriz/id/58

Guillén-Correas, Roberto \& Peñarrubia-Lozano, Carlos (2013). Incorporación de contenidos de actividades en el medio natural mediante la investigación-acción colaborativa. Retos: Nuevas Tendencias en Educación Física, Deporte y Recreación, 23, 23-28. Disponible en: http://www.redalyc. org/pdf/3457/345732289005.pdf
Gutiérrez-Cordero, Rosario; Cremades-Begines, Antonio \& Perea-Díaz, Benjamín (2011). La interdisciplinariedad de la música en la etapa de educación primaria. Espacio y Tiempo. Revista de Ciencias Humanas, 25, 151-161. Disponible en: https://dialnet.unirioja.es/descarga/articulo/ 3877921.pdf

Halai, Nelofer (2012). Developing Understanding of Innovative Strategies of Teaching Sciences through Action Research: A Qualitative Meta-synthesis from Pakistan. International Journal of Sciences and Mathematics Education, 10 (2), 387-415.

Hernández-Doria, Carlos Andrés; Gómez-Zermeño, Marcela Georgina \& Balderas-Arredondo, Maricela (2014). Inclusión de las tecnologías para facilitar los procesos de enseñanza-aprendizaje en ciencias naturales. Revista Electrónica Actualidades Investigativas en Educación, 14 (3), 1-19. Disponible en: http://www.redalyc.org/ pdf/447/44732048010.pdf

Hernández-Gil, Teresa (2007). El aprendizaje comprensivo y creativo a partir de la investigación-acción como estrategia didáctica epistémica en la educación básica. Laurus, 13 (23), 11-35. Disponible en: http://www.redalyc.org/pdf/761/7610 2302.pdf

Herr, Kathryn \& Anderson, Gary L. (2015). The Action Research Dissertation. A Guide for Students and Faculty. $2^{\text {nd }}$ ed. Thousand Oaks, California: Sage Publications Inc.

Hidalgo, María Elena (2009). Programa de intervención para la resolución de conflictos estudiantiles dirigido a los jóvenes el séptimo $\left(7^{\circ}\right)$ grado de la UEN Liceo "Andrés Bello". Una alternativa para la inducción de Valores de la No-violencia hacia la Convivencia Ciudadana. Sapiens. Revista Universitaria de Investigación, 10 (1), 225-240. Disponible en: https://dialnet.unirioja.es/descar ga/articulo/3175962.pdf

Jimeno, María Manuela (2000). La investigación-acción en el contexto de la Educación Musical. Revista de LEEME (Lista Electrónica Europea de Música en la Educación), 5, 1-6. Disponible en: http:// musica.rediris.es/leeme/revista/jimeno00.pdf

Kemmis, Stephen \& McTaggart, Robin (1998). Cómo planificar la investigación-acción. Barcelona: Laertes.

Latorre, Antonio (2003). La investigación-acción. Conocer y cambiar la práctica educativa. Barcelona: Graó.

Lewin, Kurt (1946). Action Research and Minority Problems. Journal of Social Issues, 2 (4), 34-46.

Lleixà, Teresa; Torralba, Miguel Ángel \& Abrahão, Sergio Roberto (2010). Evaluación de competencias en Educación Física: Investigación-acción para el diseño de procedimientos de evaluación en 
la Etapa Primaria. Movimiento, 16 (4), 33-51. Disponible en: http:// www.redalyc.org/articulo.oa?id $=115316963003$

López, Ana Manuela \& Lacueva, Aurora (2007). Proyectos en el aula: cinco categorías en el análisis de un caso. Revista Electrónica Iberoamericana sobre Calidad, Eficacia y Cambio en la Educación, REICE, 5 (1), 78120. Disponible en: http://www.redalyc.org/pdf/551/55100106.pdf

López-Pastor, Víctor M. (2008). La importancia del trabajo colaborativo para el tratamiento de la motricidad infantil. Una propuesta integral a partir del aprendizaje inducido. Revista Española de Pedagogía, LXVI (239), 137-150. Disponible en: https://dialnet.unirioja.es/descar ga/articulo/2595626.pdf

Mántica, Ana María \& Carbó, Ana Laura (2013). Interacciones en el aula de secundaria acerca de la dualidad infinito actual infinito potencial en un contexto geométrico. Educación Matemática, 25 (3), 27-59. Disponible en: http://www.redalyc.org/pdf/405/40529854003.pdf

Margallo-González, Ana María (2009). Lectura, escritura y aprendizaje literario en los proyectos de trabajo escolar. Lectura y Vida. Revista Latinoamericana de Lectura, 30 (3), 44-55. Disponible en: http://www. lecturayvida.fahce.unlp.edu.ar/numeros/a30n3/30_03_Margallo.pdf

Marín-Regalado, María Nieves (2012). La expresión corporal como instrumento para resolver conflictos en el aula de educación física. EmásF, Revista Digital de Educación Física, 3 (14), 122-141. Disponible en: http://emasf.webcindario.com/LA EXPRESION CORPORAL INSTRU MENTOS_DE_RESOLUCION_DE_CONFLICTOS.pdff

McKernan, James (1999). Investigación-acción y curriculum, métodos y recursos para profesionales reflexivos. Madrid: Ediciones Morata.

McNiff, Jean (2014). Writing and Doing Action Research. London: Sage Publications.

Membiela, Pedro (2002). Investigación-acción en el desarrollo de proyectos curriculares innovadores de ciencias. Enseñanza de las Ciencias, 20 (3), 443-450. Disponible en: http://www.raco.cat/index.php/en senanza/article/viewFile/21835/21669

Menéndez-Santurio, José Ignacio \& Fernández-Río, Javier (2014). Innovación en educación física: el kickboxing como contenido educativo. Apunts. Educación Física y Deportes, 117 (3), 33-42. Disponible en: http://www.raco.cat/index.php/ApuntsEFD/article/ viewFile/280882/368546

Monzonís-Martínez, Núria \& Capllonch-Bujosa, Marta (2014). La educación física en la consecución de la competencia social y ciudadana. Retos. Nuevas Tendencias en Educación Física, Deporte y Recreación, 25, 180-185. Disponible en: http://www.retos.org/nume ro_25/180-185.pdf

Navarro-Adelantado, Vicente \& Jiménez-Jiménez, Francisco (2012). La mejora en la evaluación formativa de maestros de educación física a través de un instrumento de metaevaluación didáctica. RICYDE. Revista Internacional de Ciencias del Deporte, 27 (8), 63-79. Disponible en: http://www.cafyd.com/REVISTA/02705.pdf

Oriol-López, María Ángeles (2009). Actitudes que desarrollan los alumnos de secundaria al crear composiciones musicales en grupo. Revista Electrónica Complutense de Investigación en Educación Musical, RECIEM, 6 (1), 1-10. Disponible en: http://pendientedemigracion.ucm. es/info/reciem/v6n1.pdf

Palazón-Herrera, José (2013). ¿Es efectivo el podcasting/vodcasting? Investigación-acción en el aula de música en educación secundaria. 
Píxel-Bit. Revista de Medios y Educación, 43, 51-64. Disponible en: http://www.redalyc.org/articulo.oa?id=36828074005

Pareja-Fernández de la Reguera, José A. \& Pedrosa-Vico, Beatriz (2012). Mejora de la convivencia a través de la investigación-acción participativa. Profesorado. Revista de Currículum y Formación de Profesorado, 16 (3), 467-491. Disponible en: http://www.ugr.es/ recfpro/ rev163COL14.pdf

Pérez-Rodríguez, Sandra Emilce (2011). Educación ambiental: estrategia en la enseñanza de contaminación en fuentes hídricas. Luna Azul, 33, 10-14.

Pérez-Serrano, Gloria (1990). Investigación-acción. Aplicaciones al campo social y educativo. Madrid: Dykinson.

Perseguer, Carme (2012). Identificación de los elementos de gestión del aula mediante la investigación-acción. Enseñanza de las Ciencias, 30 (3), 257-279. Disponible en: http://www.raco.cat/index.php/Ense nanza/article/view/285693/373665

Pimentel-Lorente, Aurelia (2000). Una experiencia de aproximación a la investigación-acción en el área de educación musical de la etapa primaria. Revista de LEEME (Lista Electrónica Europea de Música en la Educación), 5, 1-5. Disponible en: https://ojs.uv.es/index.php/LEEME/ article/view/9710/9146

Pineda-Alfonso, José Antonio (2013). El conflicto y la convivencia. Una investigación con alumnos de $4^{\circ}$ de ESO de un barrio periférico de la ciudad de Sevilla. Enseñanza de las Ciencias Sociales, 12, 111-118. Disponible en: http://www.raco.cat/index.php/EnsenanzaCS/article/ download/271373/359025

Quero-Ramones, Sandra \& Madueño-Madueño, Leonel (2006). Süchiki Walekerü: un ejemplo del uso de las TIC en escuelas indígenas, caso Wayuu. Educere: Revista Venezolana de Educación, 10 (34), 435-442. Disponible en: http://www.redalyc.org/articulo.oa?id=35603406

Ramírez, Zonaida \& Chacón, Carmen Teresa (2007). La promoción de la lectura significativa de textos en inglés en el noveno grado de educación básica. Educere: Revista Venezolana de Educación, 11 (37), 297-305. Disponible en: http://www.redalyc.org/articulo.oa?id=35603716

Randolph, Justus J. (2009). A Guide to Writing the Dissertation Literature Review. Practical Assessment, Research \& Evaluation, 14 (13), 1-13. Disponible en: http://pareonline.net/pdf/v14n13.pdf

Reason, Peter \& Bradbury, Hilary (2001). The Sage Handbook of Action Research. Participative Inquiry and Practice. London: Sage.

Restrepo-Gómez, Bernardo (2004). La investigación-acción educativa y la construcción de saber pedagógico. Educación y Educadores, 7, 4555. Disponible en: http://www.redalyc.org/pdf/834/83400706.pdf

Rincón-Hernández, Diana Marcela (2013). Pensamiento algebraico: una experiencia de aula, apoyada por TIC, sobre ecuaciones lineales con estudiantes de grado noveno. Revista Científica, edición especial, 665-669. Disponible en: http://funes.uniandes.edu.co/6733/1/Rin con2013Pensamiento.pdf

Ríos-Cortázar, Víctor; Gasca-García, Alejandra; Franco-Martínez, Mónica \& Tolentino-Mayo, Lizbeth (2014). Narrativa infantil en entornos escolares. Una estrategia de promoción de la salud. Salud Pública de México, 56 (2), S130-S138. Disponible en: http://www.redalyc.org/ pdf/106/10632375005.pdf

Romera-Iruela, María Jesús (2014). La investigación-acción en didáctica de las ciencias: perspectiva desde las revistas españolas de educación. Enseñanza de las Ciencias, 32 (1), 221-239. Disponible en: http://studylib. 
es/doc/7613961/la-investigaci\%C3\%B3nacci\%C3\%B3n-en-did\%C3\%A1ctica-de-lasciencias--per...

Rosas, Minerva; Jiménez, Pablo \& Ulloa, Paula (20042005). Comprensión lectora y estrategias de enseñanza y aprendizaje. Un caso de investigación acción. Lenguas Modernas, 30, 57-80. Disponible en: http://www.lenguasmodernas.uchile.cl/ index.php/LM/article/view/45395/47449

Rowell, Lonnie R.; Polush, Elena Yu; Riel, Margaret \& Bruewer, Aaron (2015). Action Researchers' Perspectives about the Distinguishing Characteristics of Action Research: A Delphi and Learning Circles Mixed-Methods Study. Educational Action Research, 23 (2), 243-270. DOI: 10.1080/09650792.2014.990987

Ruiz, Deyse \& García, Marianela (2003). El lenguaje como mediador en el aprendizaje de la aritmética en la primera etapa de educación básica. Educere: Revista Venezolana de Educación, 23, 321-327.

Santos-Rodríguez, Luis \& Fernández-Río, Javier (2012). Uso pedagógico del blog: un proyecto de investigación-acción en la materia de educación física en educación secundaria. Edutec, Revista Electrónica de Tecnología Educativa, 42, 1-14. Disponible en: http://www.edutec.es/revista/index. php/edutec-e/article/viewFile/349/88

Schön, Donald A. (1998). El profesional reflexivo. Barcelona: Paidós.

Silva-Alayón, Darwin Jesús (2010). De lo real a lo formal en matemática. Integra Educativa, 3 (2), 157178. Disponible en: http://www.scielo.org.bo/ pdf/rieiii/v3n2/a06.pdf

Stenhouse, Lawrence (1987). La investigación como base de la enseñanza. Madrid: Morata.

Terán de Serrentino, Miriam \& Pachano-Rivera, Lizabeth (2009). El trabajo cooperativo en la búsqueda de aprendizajes significativos en clase de matemáticas de la educación básica. Educere: Revista Venezolana de Educación, 13 (44), 159167. Disponible en: http://www.redalyc.org/ar ticulo.oa?id=35614571019

Toloza, Helda; Barletta, Norma \& Moreno, Francisco (2013). Una experiencia de acompañamiento en el proceso de enseñanza y aprendizaje de la lectura y la escritura en educación media. Zona Próxima, 19, 39-55. Disponible en: http://www. redalyc.org/pdf/853/85329192004.pdf

Torres-Escobar, Adriana Carolina (2014). Argumentación en la escuela primaria: trabajo colaborativo y B-Learning. Enunciación, 19 (2), 237-251. Disponible en: http://revistas.udistrital.edu.co/ojs/ index.php/enunc/article/view/7537/10041
Trejo-Castro, José Augusto \& Marcano, Noris (2013). Propuesta de innovación educativa mediante el uso de las TIC para la promoción de valores ambientales en la educación primaria venezolana. Revista de Investigación, 79 (37), 33-48. Disponible en: http://www.redalyc.org/articulo. oa?id=376140394002

Vaca-Escribano, Marcelino Juan (2010). Teorías y prácticas de calidad en educación física. Una unidad (didáctica) de investigación-acción. Ágora para la EF y el Deporte, 12 (3), 289-307. Disponible en: https://dialnet.unirioja.es/descarga/articu lo/3354740.pdf

Valero-Alemán, Patricia \& Mayora, Freddy (2009). Estrategias para el aprendizaje de la química de noveno grado apoyadas en el trabajo de grupos cooperativos. Sapiens. Revista Universitaria de Investigación, 10 (1), 109-135. Disponible en: https://dialnet.unirioja.es/descarga/articu lo/3175952.pdf

Vargas, César \& Estupiñán, María Rosa (2012). Estrategias para la educación ambiental con escolares pobladores del páramo Rabanal (Boyacá). Luna Azul, 34, 10-25. Disponible en: http://www.scie lo.org.co/pdf/luaz/n34/n34a02.pdf

Vásquez-Arenas, Esperanza; Becerra-Galindo, Aurora \& Ibáñez-Córdoba, Sandra Ximena (2014). La investigación dirigida como estrategia para el desarrollo de competencias científicas. Revista Científica, 1 (18), 77-85. Disponible en: http:// revistas.udistrital.edu.co/ojs/index.php/revcie/ar ticle/view/5563/7077

Vaughan, Michelle \& Burnaford, Gail (2016). Action Research in Graduate Teacher Education: A Review of the Literature 2000-2015. Educational Action Research, 24 (2), 280-299. DOI: 10.1080/09650792.2015.1062408. Disponible en: http://www.coe.fau.edu/faculty/mvaugha3/ documents/ARinGraduateteacherEd.pdf

Villagra-Bravo, Carolina \& Castillo-Melgarejo, Cristhian (2010). La utilización de documentos de archivo: una experiencia de investigación-acción en el subsector de historia y ciencias sociales. REXE. Revista de Estudios y Experiencias en Educación, 9 (18), 65-74. Disponible en: http://www.redalyc. org/articulo.oa?id=243119055005

Zárate, Mario (2012). El texto biográfico como propuesta didáctica para fortalecer la comunicación escrita en estudiantes de educación secundaria. Punto Cero, 17 (25), 27-36. Disponible en: http:// www.redalyc.org/pdf/4218/421839653004.pdf

Zuber-Skerritt, Ortrun \& Fletcher, Margaret (2007). The Quality of an Action Research Thesis in the Social Sciences. Quality Assurance in Education, 15 (4), 413-436. DOI 10.1108/09684880710829983 
Ander-Egg, Ezequiel (2003). Repensando la investigación-acción-participativa. Comentarios, críticas y sugerencias. Buenos Aires: Lumen.

Arellano, N. (2004). ¿Cómo elaborar un proyecto de investigación acción? Parte I. Colegio Belagua.

Bennett, Christine K. (1994). Promoting Teacher Reflection through Action Research: What Do Teachers Think? Journal of Staff Development, 15 (1), 34-38.

Escudero-Muñoz, Juan M. (1987). La investigación-acción en el panorama actual de la investigación educativa: algunas tendencias. Revista de Investigación e Innovación Educativa, 3, 5-39.

Fraile-Aranda, Antonio (1991). La investigación-acción: método de análisis para una nueva educación física. Revista Interuniversitaria de Formación del Profesorado, 10, 251-264. Disponible en: https://dialnet. unirioja.es/servlet/articulo?codigo $=117746$

Goyette, Gabriel \& Lessard-Hébert, Michelle (1998). La investigación-acción. Funciones, fundamentos e instrumentación. Barcelona: Laertes.

James, E. Alana; Milenkiewicz, Margaret T. \& Bucknam, Alan (2008). Participatory Action Research for Education Leadership: Using Data-Driven Decision Making to Improve Schools. Los Ángeles: Sage.

López de Ceballos, Paloma (1998). Un método para la investigación-acción participativa. Madrid: Popular.

McNiff, Jean \& Whitehead, Jack (2006). All You Need to Know about Action Research. London: Sage.

Oja, Sharon Nodie \& Smulyan, Lisa (1989). Collaborative Action Research: A Developmental Approach. Lewes, East Sussex: Falmer Press.

Rahman, Mohammad Anisur \& Fals-Borda, Orlando (1989). La situación actual y las perspectivas de IAP en el mundo. En María Cristina Salazar (ed.). La investigación acción participativa, 205-223. Bogotá: Cooperativa Editorial Magisterio.

Rojas-Soriano, Raúl (1999). Investigación-acción en el aula. Enseñanzaaprendizaje de la metodología. México: Plaza y Valdés Editores.

Sagor, Richard (1992). How to Conduct Collaborative Action Research. Alexandria, Virginia: Association for Supervision and Curriculum Development, ASCD. 